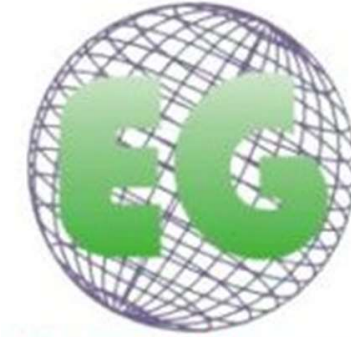

ISSN 1695-6141 N'57

\title{
Perfil epidemiológico y clínico de casos de microcefalia
}

Perfil epidemiológico e clínico de casos de microcefalia

Epidemiological and clinical profile of microcephaly cases

Evelyn Maria Braga Quirino'

Clarissa Mourão Pinho²

Mônica Alice Santos da Silva ${ }^{3}$

Cynthia Angélica Ramos de Oliveira Dourado ${ }^{2}$

Morgana Cristina Leôncio de Lima ${ }^{3}$

Maria Sandra Andrade ${ }^{4}$

1 Enfermera de Infectología. Alumna de Maestría en Enfermería por el Programa Asociado de Postgrado UPE/UEPB. Brasil. evelynquirino@hotmail.com

2 Maestra en Enfermería por el Programa Asociado de Postgrado UPE/UEPB. Alumna de Doctorado en Enfermería por el Programa Asociado de Postgrado UPE/UEPB. Brasil.

${ }^{3}$ Alumna de Maestría en Enfermería por el Programa Asociado de Postgrado UPE/UEPB. Brasil.

4 Postdoctorado en Salud Pública. Profesora de Enfermería del Programa Asociado de Postgrado UPE/UEPB. Brasil.

\section{http://dx.doi.org/10.6018/eglobal.19.1.366701}

Recibido: $10 / 03 / 2019$

Aceptado: 23/06/2019

\section{RESUMEN}

Objetivo: Describir el perfil epidemiológico y clínico de los casos de microcefalia en Recife, Pernambuco.

Método: Estudio transversal, cuantitativo, desarrollado en un hospital de referencia para casos de microcefalia. Los datos se recolectaron en agosto/2016 sobre la base del formulario FormSUS. Se incluyeron todos los casos de microcefalia confirmados de agosto/2015 a julio/2016, totalizando 180 casos. Para analizar los datos, se utilizó la estadística descriptiva y las pruebas de Chi-cuadrado y exacta de Fisher.

Resultados: La mayoría de los casos tuvieron lugar en octubre y noviembre de 2015 , con $55(30,6 \%)$ y $52(28,9 \%)$, respectivamente. La serología para el virus Zika fue reactiva para $79(43,9)$ bebés. El síntoma más prevalente durante el embarazo fue la erupción cutánea, 105 (57,3\%). Además, 150 $(83,3 \%)$ niños nacieron a término, $78(43,3 \%)$ presentaron percentiles entre 10 y 50 en la relación peso y edad gestacional y $108(60 \%)$ tuvieron -3 desviaciones estándar en la comparación del perímetro cefálico con la edad gestacional, considerada como microcefalia grave.

Conclusiones: Es necesario garantizar a estos niños una atención integral y especializada. Es imprescindible la vigilancia epidemiológica y entomológica, así como y acciones de control más eficaces en la lucha contra el vector.

Palabras clave: Microcefalia; Infecciones por Arbovirus; Virus Zika; Enfermería en Salud Pública.

\section{RESUMO}

Objetivo: Descrever o perfil epidemiológico e clínico dos casos de microcefalia em Recife, Pernambuco. 
Método: Estudo transversal, quantitativo, desenvolvido em hospital de referência para casos de microcefalia. Os dados foram coletados em agosto/2016 a partir do formulário FormSUS. Foram incluídos todos os casos de microcefalia confirmados de agosto/2015 a julho/2016, perfazendo 180 casos. Para análise dos dados utilizou-se a estatística descritiva e os testes do qui-quadrado e exato de Fisher.

Resultados: A maioria dos casos ocorreram em outubro e novembro de 2015, com 55 (30,6\%) e 52 $(28,9 \%)$, respectivamente. A sorologia para o vírus Zika foi reagente para $79(43,9 \%)$ dos bebês. O sintoma mais prevalente, durante a gestação, foi o exantema 105 (57,3\%). Ademais, 150 (83,3\%) crianças nasceram a termo, $78(43,3 \%)$ apresentaram percentis entre 10 e 50 na relação peso e idade gestacional e 108 (60\%) possuíam -3 desvios padrões na comparação do perímetro cefálico com a idade gestacional, considerada microcefalia severa.

Conclusões: É necessário garantir a essas crianças um atendimento integral e especializado. É imprescindível a vigilância epidemiológica, entomológica e ações de controle mais efetivas no combate ao vetor.

Palavras-Chave: Microcefalia; Infecções por Arbovirus; Zika Vírus; Enfermagem em Saúde Pública.

\begin{abstract}
Objective: To describe the epidemiological and clinical profile of microcephaly cases in Recife, Pernambuco.

Method: This was a cross-sectional, quantitative study developed at a reference hospital for cases of microcephaly. Data were collected in August 2016 from the FormSUS system. All confirmed cases of microcephaly in the period from August 2015 to July 2016 were included, making up 180 cases. Data were analyzed using descriptive statistics and the chi-square and Fisher's exact tests.

Results: The majority of cases occurred in October and November 2015, with $55(30.56 \%)$ and 52 $(28.89 \%)$ cases, respectively. Serology for the Zika virus was reagent for $79(43.89 \%)$ of the infants. The most prevalent symptom during gestation was exanthema 105 (57.3\%). Furthermore, 150 (83.33\%) of the children were born at full term, $78(43.33 \%)$ presented percentiles between 10 and 50 in relation to weight and gestational age and $108(60 \%)$ had -3 standard deviations in the comparison of head circumference with gestational age, thus considered to indicate severe microcephaly.

Conclusions: It is necessary to guarantee comprehensive and specialized care for these children. Epidemiological and entomological surveillance and more effective control actions in the fight against the vector are necessary.
\end{abstract}

Descriptors: Microcephaly; Arbovirus Infections; Zika Virus; Public Health Nursing.

\title{
INTRODUCCIÓN
}

En 2015, tuvo lugar en Brasil una epidemia causada por arbovirus transmitidos por el mosquito Aedes aegypti. Entre estas arbovirosis, se destaca la infección por el virus Zika (ZIKV), relacionada con los casos de microcefalia, que acarrean un cambio en el escenario epidemiológico y alteraciones congénitas en niños recién nacidos ${ }^{(1-3)}$.

El ZIKV se aisló por primera vez en 1947 de la sangre de un mono en el Valle de Zika en Uganda, y los primeros informes en humanos tuvieron lugar en 1952 en Uganda y Tanzania ${ }^{(2-5)}$. Se han reportado pocos casos de infección en seres humanos hasta el año 2007, cuando tuvo lugar la primera epidemia de ZIKV en el Estado de Yap, uno de los cuatro Estados Federados de Micronesia. En 2013, se reportó un nuevo brote en la Polinesia Francesa, Nueva Caledonia; y, en 2015, investigadores brasileños aislaron el virus por primera vez en Bahía. ${ }^{(6-7)}$.

Se trata de una infección transmitida por mosquitos artrópodos, generalmente asintomáticos o con síntomas leves como fiebre, eritema y artralgia, y que presenta un tropismo por el sistema nervioso ${ }^{(4,8)}$. Otras formas de contaminación además del vector han sido reportadas como la congénita, la sexual y mediante transfusiones de sangre ${ }^{(9,10)}$. En la mayoría de los casos, la enfermedad es asintomática, pero puede 
ocurrir con gravedad debido a casos de microcefalia y síndrome de Guillain-Barré asociados con el virus ${ }^{(11)}$.

Los estudios señalan que el incremento en el número de casos de microcefalia en Brasil, principalmente en el Noreste del país, fue consecuencia de la infección causada por el ZIKV en mujeres en edad fértil. Estos hallazgos se confirmaron después del aislamiento viral en el líquido amniótico de dos mujeres embarazadas que tenían un diagnóstico fetal de microcefalia y presentaron signos y síntomas de arbovirosis, además de una autopsia de un aborto fetal de una mujer europea que residía en el país hasta el inicio del embarazo ${ }^{(2,3)}$. Los resultados presentados en una revisión sistemática corroboran con estos hallazgos, donde hubo una relación causal entre el ZIKV y las anomalías congénitas ${ }^{(12)}$.

La microcefalia es un hallazgo clínico resultante de factores genéticos o no genéticos. La Organización Mundial de la Salud (OMS) considera la microcefalia cuando el recién nacido $(R N)$ tiene un perímetro cefálico $(P C)$ inferior a -2 o más desviaciones estándar y microcefalia grave cuando mide menos de -3 desviaciones estándar. Esta medida debe ser realizada por un profesional calificado, con equipo y herramientas estandarizadas, 24 horas después del nacimiento y dentro de la primera semana de vida (hasta 6 días y 23 horas) ${ }^{(13)}$.

Después del diagnóstico de microcefalia, es necesario un seguimiento periódico para evaluar su gravedad y su posible retraso mental. En un estudio publicado en 1968, con 212 niños con microcefalia, se demostró la correlación entre la circunferencia del perímetro cefálico y el retraso mental, es decir, cuanto menor es la circunferencia, mayor es la gravedad del caso ${ }^{(14)}$. Para establecer la etiología y la gravedad de la microcefalia, es necesario realizar una prueba de neuroimagen que permita una mejor visualización de las áreas afectadas. Los estudios internacionales describen como un gran hallazgo la reducción en el tamaño del sistema nervioso central (SNC), sobre todo en la corteza cerebral (13-15).

La microcefalia asociada con ZIKV es una emergencia mundial en Salud Pública (16) que necesita ser mejor estudiada. Por lo tanto, se considera importante conocer los aspectos clínicos y epidemiológicos relacionados con esto arbovirus, buscando ofrecer subvenciones para que los profesionales de la salud puedan desarrollar líneas de atención que sean esenciales para actuar en las diferentes fases del desarrollo de estos niños. Desde esta perspectiva, este estudio pretende describir el perfil epidemiológico y clínico de los casos de microcefalia en Recife, Pernambuco.

\section{METODOLOGÍA}

\section{Escenario y tipo de estúdio}

Se trata de un estudio transversal con enfoque cuantitativo, desarrollado en el Centro de Vigilancia Epidemiológica del Entorno Hospitalario del Hospital Universitario Oswaldo Cruz (VEAH-HUOC), una unidad estatal de referencia en la atención a los niños con microcefalia.

La recolección de datos se llevó a cabo en agosto de 2016 sobre la base de los formularios de notificación en el formulario FormSUS. 


\section{Población}

La población del estudio se compuso de 455 casos notificados de microcefalia asistidos desde agosto de 2015 hasta julio de 2016.

\section{Definición de la muestra}

Se consideraron los siguientes criterios: casos notificados de RN con menos de 37 semanas de edad gestacional, presentando un perímetro cefálico inferior a -2 o más desviaciones estándar, según la tabla Intergrowth, y los RN con 37 semanas o más de edad gestacional que presentaban perímetro cefálico menor o igual a $31,5 \mathrm{~cm}$ para las niñas y $31,9 \mathrm{~cm}$ para los niños y que se confirmaron mediante pruebas de imagen (ultrasonido transfontanelar [US-TF] y/o tomografía computarizada de cráneo [TCC] o imágenes de resonancia magnética) y/o pruebas de laboratorio [relacionadas con la infección congénita por STORCH y/o la infección por el Vírus Zika en RN y madres]) $(16,17)$.

\section{Criterios de inclusión y exclusión}

Nacidos vivos, notificados por el núcleo VEAH-HUOC, que tuvieron un diagnóstico de microcefalia intrauterina y/o después del nacimiento. Se excluyeron del estudio aquellos que fueron dados de alta después de la exclusión de la microcefalia y aquellos que estaban bajo investigación en el momento de la recolección de datos. La muestra se compuso de 180 casos confirmados de microcefalia.

\section{Variables de estudio}

Las variables utilizadas se tomaron del formulario FormSUS y se clasificaron en sociodemográficas (sexo, área de vivienda y mesorregión); relacionadas con el nacimiento y el embarazo (edad de la madre, mes de nacimiento, edad gestacional en el momento del parto, perímetro cefálico al nacer, peso x edad gestacional, perímetro cefálico $\mathrm{x}$ edad gestacional); relacionadas con la presencia de signos y síntomas de infección por ZIKV durante el embarazo (erupción cutánea, presencia de fiebre, dolor articular y trimestre gestacional en el que se produjeron signos y síntomas); relacionadas con pruebas de imagen para la confirmación de la infección por ZIKV (US-TF, TCC); $y$, por último, relacionadas con pruebas complementarios (ecocardiograma, prueba de oído, fundoscopia, coinfección del RN, serología para ZIKV en el RN).

Los resultados de la TCC con calcificaciones y la medida del perímetro cefálico $x$ edad gestacional se utilizaron para verificar asociaciones con las siguientes variables: sexo, serología para ZIKV en el NB, coinfección del RN y el trimestre de gestación en el que apareció la erupción cutánea.

\section{Análisis y procesamiento de datos}

Los datos se almacenaron en una hoja de cálculo del programa informático Microsoft Excel 2013 y se exportaron al programa estadístico PASW Statistics 18. El análisis de los datos se llevó a cabo a través de estadística descriptiva, y los resultados se presentaron en frecuencias absolutas, porcentajes, medias y desviación estándar. Se utilizaron las pruebas de Chi-cuadrado y exacta de Fisher. Se sacaron todas las conclusiones considerando el nivel de significación del $5 \%$.

\section{Aspectos éticos}

El proyecto de investigación fue aprobado por el Comité de Ética en Investigación del Hospital Universitario Oswaldo Cruz, en cumplimiento de la Resolución n 466/2012 
del Consejo Nacional de Salud, con CAAE: 57736116.9.0000.5192 y Opinión n 1.675.612, expedido en 2016.

\section{RESULTADOS}

De los 455 casos notificados como sospechosos de microcefalia, 180 casos fueron confirmados por criterios clínicos y pruebas de laboratorio, como pruebas serológicas (IgM ZIKV-ELISA), reacción en cadena de polimerasa (ZIKV RT-PCR) y pruebas de imagen (US-TF y TCC). Además, 57 pacientes estaban bajo investigación en el momento de la recolección y 218 casos notificados se descartaron después de la obtención de imágenes y la atención clínica. La muestra estudiada $(n=180)$ reveló un predominio de mujeres, procedentes de la Región Metropolitana de Recife y que residen en la zona urbana (Tabla 1 ).

Tabla 1 - Distribución de casos confirmados de microcefalia de acuerdo con sexo, área de vivienda y mesorregión. Recife, PE, Brasil, 2016.

\begin{tabular}{lcc}
\hline \multicolumn{1}{c}{ Variables } & $\mathbf{n}$ & $\mathbf{\%}$ \\
\hline Sexo & 140 & 77,8 \\
Femenino & 40 & 22,2 \\
Masculino & & \\
Área de vivienda & 174 & 96,7 \\
Urbana & 6 & 3,3 \\
Rural & & \\
Mesorregión de vivienda & 117 & 65,0 \\
Región Metropolitana de Recife & 27 & 15,0 \\
Zona del Bosque de Pernambuco & 23 & 12,8 \\
Agreste & 10 & 5,6 \\
Sertón & 1 & 0,6 \\
Valle del Río São Francisco & 2 & 1,1 \\
Otro estado & & \\
\hline
\end{tabular}

Fuente: Centro de Vigilancia Epidemiológica del Entorno Hospitalario del Hospital Universitario Oswaldo Cruz VEAH-HUOC. Recife, Brasil, 2016.

En agosto de 2015, se inició la atención a los casos sospechosos de microcefalia, con un seguimiento. La mayoría de los bebés diagnosticados nacieron en octubre y noviembre de 2015, con $107(59,4 \%)$ casos estudiados. Más de la mitad de los niños tenían -3 desviaciones estándar en la comparación del perímetro cefálico con la edad gestacional, y se consideraron con microcefalia grave (Tabla 2).

Tabla 2 - Datos de nacimiento y embarazo de casos confirmados de microcefalia. Recife, PE, Brasil, 2016.

\begin{tabular}{|c|c|c|}
\hline 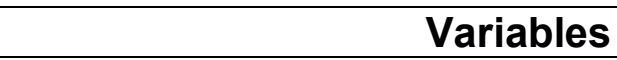 & $\mathbf{n}$ & $\%$ \\
\hline \multicolumn{3}{|l|}{ Edad de la madre } \\
\hline Inferior a 15 & 2 & 1,1 \\
\hline 15 a 24 años & 80 & 44,4 \\
\hline 25 a 34 años & 72 & 40,0 \\
\hline 35 a 44 años & 23 & 12,8 \\
\hline Sin información & 3 & 1,7 \\
\hline Mínima - Máxima & $14-43$ & \\
\hline Media \pm Desviación estándar & $26,07 \pm 7,23$ & \\
\hline Mes de nacimiento & & \\
\hline Febrero de 2015 & 1 & 0,6 \\
\hline
\end{tabular}




\begin{tabular}{|c|c|c|}
\hline Abril de 2015 & 1 & 0,6 \\
\hline Mayo de 2015 & 2 & 1,1 \\
\hline Junio de 2015 & 1 & 0,6 \\
\hline Julio de 2015 & 6 & 3,3 \\
\hline Agosto de 2015 & 4 & 2,2 \\
\hline Septiembre de 2015 & 19 & 10,6 \\
\hline Octubre de 2015 & 55 & 30,6 \\
\hline Noviembre de 2015 & 52 & 28,9 \\
\hline Diciembre de 2015 & 24 & 13,3 \\
\hline Enero de 2016 & 12 & 6,7 \\
\hline Febrero de 2016 & 2 & 1,1 \\
\hline Julio de 2016 & 1 & 0,6 \\
\hline \multicolumn{3}{|c|}{ Edad gestacional en el momento del parto } \\
\hline Pretérmino $<37$ semanas & 22 & 12,2 \\
\hline Término 37 a 41 semanas & 150 & 83,3 \\
\hline Postérmino 42 semanas o más & 8 & 4,4 \\
\hline \multicolumn{3}{|l|}{ Perímetro cefálico al nacer } \\
\hline Mínima - Máxima & $25,0-33,0$ & \\
\hline Media \pm Desviación estándar & $29,64 \pm 1,94$ & \\
\hline \multicolumn{3}{|l|}{ Peso x Edad gestacional } \\
\hline Debajo del percentil 3 & 35 & 19,4 \\
\hline Entre los percentiles 3 y 10 & 44 & 24,4 \\
\hline Entre los percentiles 10 y 50 & 78 & 43,3 \\
\hline Entre los percentiles 50 y 90 & 18 & 10,0 \\
\hline Entre los percentiles 90 y 97 & 1 & 0,6 \\
\hline Debajo del percentil 97 & 2 & 1,1 \\
\hline Sin información & 2 & 1,1 \\
\hline \multicolumn{3}{|c|}{ Perímetro cefálico $\times$ Edad gestacional } \\
\hline 0 Desviaciones estándar & 9 & 5,0 \\
\hline -1 Desviaciones estándar & 25 & 13,9 \\
\hline -2 Desviaciones estándar & 38 & 21,1 \\
\hline -3 Desviaciones estándar & 108 & 60,0 \\
\hline
\end{tabular}

Fuente: Centro de Vigilancia Epidemiológica del Entorno Hospitalario del Hospital Universitario Oswaldo Cruz VEAH-HUOC. Recife, Brasil, 2016.

Los síntomas más frecuentes reportados por las madres durante el embarazo relacionados con las arbovirosis fueron erupción cutánea, fiebre y dolor articular. De las $39(21,7 \%)$ madres que reportaron estos síntomas en el primero trimestre de embarazo, 25 (64,1\%) tenían niños diagnosticados con microcefalia grave (Tabla 3).

Tabla 3 - Distribución de los signos y síntomas de arbovirosis y trimestre de embarazo reportados por las madres. Recife, PE, Brasil, 2016.

\begin{tabular}{lcc}
\hline \multicolumn{1}{c}{ Variables } & $\mathbf{n}$ & $\%$ \\
\hline Erupción cutánea & 103 & \\
Sí & 70 & 37,2 \\
No & 7 & 3,9 \\
No lo recuerdo/No lo sé & & \\
Presencia de fiebre & 52 & 28,9 \\
Sí & 90 & 50,0 \\
No & 38 & 21,1 \\
No lo recuerdo/No lo sé & & \\
\hline
\end{tabular}




\begin{tabular}{lcc}
\hline Dolor articular & & \\
Sí & 50 & 27,8 \\
No & 91 & 50,6 \\
No lo recuerdo/No lo sé & 39 & 21,7 \\
Trimestre de embarazo & & \\
Primero & 39 & 21,7 \\
Segundo & 18 & 10,0 \\
Tercero & 8 & 4,4 \\
No lo recuerdo & 47 & 26,1 \\
No se aplica & 68 & 37,8 \\
\hline
\end{tabular}

Fuente: Centro de Vigilancia Epidemiológica del Entorno Hospitalario del Hospital Universitario Oswaldo Cruz VEAH-HUOC. Recife, Brasil, 2016.

Después de la primera asistencia en la unidad de salud, los niños se sometieron a pruebas de imagen como US-TF y TCC. De los 68 pacientes que se sometieron a USTF, $58(32,2 \%)$ presentaron alteraciones de imagen, como calcificaciones, dos tuvieron problemas en la ejecución (porque tenían la fontanela cerrada) y cinco tuvieron sus pruebas de imagen consideradas normales. De los 180 bebés, 164 $(91,1 \%)$ presentaron alteraciones en la TCC, $155(86,1 \%)$ presentaron calcificaciones, $64(35,6 \%)$ presentaron malformación del desarrollo cortical, $41(22,8 \%)$ presentaron alteraciones en la sustancia blanca, $43(23,9 \%)$ lisencefalia y $106 \quad(58,9 \%)$ ventriculomegalia.

Para un mejor seguimiento e investigación de los 180 niños, se recomendó un protocolo clínico y epidemiológico en el Estado de Pernambuco, con la solicitud de pruebas complementarias cuyos resultados se demuestran en la Tabla 4. Estas serologías también se solicitaron a 53 madres. De las pruebas realizadas en los menores, $63(35 \%)$ se realizaron a través de la recolección de líquido cefalorraquídeo (LCR).

Entre los casos asistidos y confirmados, se subraya que $119(66,1 \%)$ tuvieron su diagnóstico después del nacimiento, $163 \quad(90,6 \%)$ todavía permanecen en seguimiento, $16(8,9 \%)$ fueron transferidos y uno pasó a fallecer.

Tabla 4 - Distribución de los resultados de las pruebas complementarias realizadas en casos confirmados de microcefalia. Recife, PE, Brasil, 2016.

\begin{tabular}{lcc}
\hline \multicolumn{1}{c}{ Variables } & $\mathbf{n}$ & $\%$ \\
\hline Ecocardiograma & 21 & \\
No realizada & 34 & 11,7 \\
Esperando resultado & 71 & 18,9 \\
Normal & 54 & 39,4 \\
Alterada & & 30,0 \\
Prueba de oído & 23 & \\
No realizada & 46 & 12,8 \\
Esperando resultado & 90 & 25,6 \\
Normal & 5 & 50,0 \\
Fallo en el ó́do derecho & 2 & 2,8 \\
Fallo en el oído izquierdo & 10 & 1,1 \\
Ambos fallaron & 4 & 5,6 \\
Alterada & & 2,2 \\
Fundoscopia & 27 & 15,0 \\
No realizada & 48 & 26,7 \\
Esperando resultado & &
\end{tabular}




\begin{tabular}{lcc}
\hline Normal & 59 & 32,8 \\
Alterada & 46 & 25,6 \\
Coinfección en el RN & 34 & 18,9 \\
No realizada & 141 & 78,3 \\
Negativa & 1 & 0,6 \\
HIV & 2 & 1,1 \\
Citomegalovirus & 0 & 0,0 \\
Toxoplasmosis & 2 & 1,1 \\
Sífilis & 79 & 43,9 \\
Serología para virus Zika en el RN & 5 & 2,8 \\
Positiva & 77 & 42,8 \\
No reactiva & 19 & 10,6 \\
No realizada & & \\
Sin resultado &
\end{tabular}

Fuente: Centro de Vigilancia Epidemiológica del Entorno Hospitalario del Hospital Universitario Oswaldo Cruz VEAH-HUOC. Recife, Brasil, 2016.

De los 155 niños que presentaron calcificaciones en la TCC, se notó una mayor prevalencia $(94,6 \%)$ entre las mujeres, así como una medición de perímetro cefálico de -3DP $(62,9 \%)$. Las pruebas de independencia no fueron significativas para los factores evaluados (Tabla 5).

Tabla 5 - Distribución de los resultados de la tomografía computarizada de cráneo que presentaron calcificaciones y del perímetro cefálico $x$ edad gestacional según sexo, serología para Zika, coinfecciones y trimestre de erupción cutánea.

\begin{tabular}{|c|c|c|c|c|}
\hline \multirow[t]{2}{*}{ Factor evaluado } & \multicolumn{2}{|c|}{$\begin{array}{c}\text { TCC con } \\
\text { calcificaciones }\end{array}$} & \multicolumn{2}{|c|}{$P C \times E G$} \\
\hline & Sí & No & 0 a -2 DP & $-3 D P$ \\
\hline \multicolumn{5}{|l|}{ Sexo } \\
\hline Femenino & $122(94,6 \%)$ & $7(5,4 \%)$ & $52(37,1 \%)$ & $88(62,9 \%)$ \\
\hline Masculino & $33(94,3 \%)$ & $2(5,7 \%)$ & $20(50,0 \%)$ & $20(50,0 \%)$ \\
\hline p-valor & \multicolumn{2}{|c|}{$1,000^{2}$} & \multicolumn{2}{|c|}{$0,143^{1}$} \\
\hline \multirow{3}{*}{$\begin{array}{l}\text { Serología para Zika } \\
\text { Positiva } \\
\text { No reactiva }\end{array}$} & & & & \\
\hline & $65(90,3 \%)$ & $7(9,7 \%)$ & $28(35,4 \%)$ & $51(64,6 \%)$ \\
\hline & $5(100,0 \%)$ & $0(0,0 \%)$ & $4(80,0 \%)$ & $1(20,0 \%)$ \\
\hline$p$-valor & \multicolumn{2}{|c|}{$1,000^{2}$} & \multicolumn{2}{|c|}{$0,067^{2}$} \\
\hline \multirow{3}{*}{$\begin{array}{l}\text { Coinfección } \\
\text { Sí } \\
\text { No }\end{array}$} & & & & \\
\hline & $4(100,0 \%)$ & $0(0,0 \%)$ & $2(40,0 \%)$ & $3(60,0 \%)$ \\
\hline & $124(95,4 \%)$ & $6(4,6 \%)$ & $54(38,3 \%)$ & $87(61,7 \%)$ \\
\hline$p$-valor & \multicolumn{2}{|c|}{$1,000^{2}$} & \multicolumn{2}{|c|}{$1,000^{2}$} \\
\hline \multicolumn{5}{|l|}{$\begin{array}{l}\text { Trimestre de } \\
\text { erupción cutánea }\end{array}$} \\
\hline $1^{\circ}$ trimestre & $33(94,3 \%)$ & $2(5,7 \%)$ & $14(35,9 \%)$ & $25(64,1 \%)$ \\
\hline $2^{\circ}$ ou $3^{\circ}$ trimestre & $24(100,0 \%)$ & $0(0,0 \%)$ & $10(38,5 \%)$ & $16(61,5 \%)$ \\
\hline No lo recuerdo & $43(93,5 \%)$ & $3(6,5 \%)$ & $17(36,2 \%)$ & $30(63,8 \%)$ \\
\hline No se aplica & $55(93,2 \%)$ & $4(6,8 \%)$ & $31(45,6 \%)$ & $37(54,4 \%)$ \\
\hline p-valor & \multicolumn{2}{|c|}{$0,721^{2}$} & \multicolumn{2}{|c|}{$0,689^{1}$} \\
\hline
\end{tabular}

Fuente: Centro de Vigilancia Epidemiológica del Entorno Hospitalario del Hospital Universitario Oswaldo Cruz VEAH-HUOC. Recife, Brasil, 2016. 


\section{DISCUSIÓN}

Hasta el 30 de julio de 2016, Brasil notificó 8.801 casos sospechosos de microcefalia, de los cuales 1.773 fueron confirmados. De estos, 1.510 son del Noreste de Brasil y Pernambuco lidera el número de notificaciones con 376 casos. La unidad de referencia estudiada notificó el $10,2 \%$ de los casos a escala nacional, siendo el 11,9\% en relación con el Noreste y el $47,9 \%$ de las notificaciones del estado de Pernambuco ${ }^{(16,17)}$.

Con el fin de mejorar el monitoreo de los casos a nivel nacional, desde agosto de 2016, la notificación de casos de microcefalia se lleva a cabo mediante los Registros de Eventos de Salud Pública. En 2017, la enfermedad dejó de ser un problema de emergencia en salud pública, pero los casos existentes requieren acciones de promoción de la salud y seguimiento clínico durante toda la vida ${ }^{(13,17)}$.

La atención a los niños con sospecha de microcefalia desde diciembre de 2015 se ha llevado a cabo en 18 unidades de referencia divididas en 4 macrorregiones distribuidas en la Región Metropolitana, Agreste, Sertón, Valle de São Francisco y Araripe en el Estado de Pernambuco. La unidad en la que se llevó a cabo esta investigación está ubicada en la macrorregión I, que junto con otras 6 unidades, abarcan la atención en 72 ayuntamientos de la Región Metropolitana ${ }^{(16,12)}$.

Diversos factores ambientales causan malas formaciones fetales, entre ellos el etanol, las drogas, el mercurio, la radiación y ciertos agentes virales que pueden afectar el desarrollo cortical del feto. Las infecciones virales intrauterinas asociadas con daño del SNC se consideran raras, pero después de la entrada del virus Zika en el país, se notaron casos de microcefalia relacionados con dicho virus ${ }^{(18)}$. En este estudio, de los 84 niños que se sometieron a una prueba de laboratorio y donde el resultado estaba disponible, el $94 \%$ tuvieran resultados positivos para ZIKV.

La evidencia científica sobre la asociación de ZIKV y microcefalia es muy consistente. Un estudio brasileño, publicado en mayo de 2016, que analizó 5 casos sospechosos de ZIKV, tuvo resultados diversificados. En el primero caso, un bebé nacido a término no presentó microcefalia, aunque su madre presentó signos y síntomas y una serología positiva para ZIKV durante el octavo mes de embarazo. El segundo caso fue de una mujer de 31 años que se sometió a un aborto semanas después de presentar un cuadro clínico compatible con la enfermedad. Los últimos tres casos fueron de recién nacidos con pruebas positivas para el virus, que fallecieron menos de 24 horas después del nacimiento ${ }^{(19)}$.

Los resultados preliminares de un estudio de casos control, con 32 casos y 64 controles, sugieren que la epidemia de microcefalia es el resultado de una infección congénita, ya que el $80 \%$ de los casos fueron positivos para los anticuerpos específicos contra el ZIKV. Los resultados finales de este estudio, cuyo objetivo fue evaluar las asociaciones de microcefalia con la infección congénita por el ZIKV y con el uso de vacunas y larvicidas, demostraron la asociación entre microcefalia e infección congénita por el ZIKV y la no asociación de microcefalia con la vacunación durante el embarazo y el uso de larvicida piriproxifeno ${ }^{(20)}$.

Al analizar los signos y síntomas de la infección por el ZIKV en mujeres embarazadas, se puede notar que la erupción cutánea fue reportada por poco más de la mitad de las encuestadas. Otros signos y síntomas característicos de la enfermedad estaban ausentes en aproximadamente la mitad de los casos o las mujeres embarazadas informaron que no recordaban o no sabían como informar, lo que puede caracterizar 
cuadros asintomáticos u oligosintomáticos. En un estudio realizado en 2009 , el $80 \%$ de las personas infectadas no informaron síntomas característicos de la enfermedad $^{(21)}$.

En un estudio brasileño que abarcó 88 mujeres embarazadas de diferentes edades gestacionales y que presentaban signos y síntomas característicos de las arbovirosis, 72 tuvieron un resultado positivo para el ZIKV, siendo que $46(63,9 \%)$ tuvieron dolor articular y $20(27.8 \%)$ presentaron fiebre ${ }^{(22)}$. La erupción cutánea se notó en todas las mujeres embarazadas, ya que es un criterio de inclusión del estudio y no es comparable a la muestra en cuestión.

Los meses de octubre y noviembre de 2015 concentraron la mayor cantidad de niños con microcefalia. Al segmentar los trimestres gestacionales de un embarazo a término, se verifica que el primero y segundo trimestres ocurrieron durante el verano brasileño, período de incremento en el número de mosquitos Aedes aegypti. Estos viven bien adaptados en las zonas urbanas y son transmisores de las arbovirosis como Dengue, virus Zika y Chicunguña ${ }^{(23)}$. Así, el incremento en el número de casos de arbovirosis y de malformación de los niños puede estar relacionado con el período estacional de mayor incidencia del mosquito. Además, el $96,7 \%$ de las madres residían en áreas urbanas.

Los países con clima tropical tienen una posición destacada en la transmisión de arbovirosis. Además de la extensión territorial de Brasil para permitir las diferencias climáticas regionales, todavía existen desigualdades en la distribución de la red de saneamiento básico e hídrico que implican un mayor riesgo de enfermedad a través de patologías transmitidas por Aedes aegypti (24).

En este estudio, fue posible observar la presencia de casos de microcefalia con un perímetro cefálico de hasta $33 \mathrm{~cm}$. Este hecho se debe al protocolo adoptado al inicio del brote, que guió la notificación de los recién nacidos, entre las 37 y 42 semanas de embarazo, con un perímetro cefálico medido al nacer igual o inferior a $33 \mathrm{~cm}$, en la curva de la OMS ${ }^{(25)}$. A continuación, después del surgimiento de nuevas pruebas de los estudios de campo, se redujo la medida de referencia del perímetro cefálico a 32 $\mathrm{cm}$ en los niños a término de ambos sexos ${ }^{(26)}$. En marzo de 2016 , se adoptó una definición estándar internacional de microcefalia, de acuerdo con las directrices de la OMS, en la que, para los niños a término, las medidas a adoptar fueron $31,5 \mathrm{~cm}$ para las niñas y $31,9 \mathrm{~cm}$ para los niños ${ }^{(27)}$. Aunque estos casos no estaban de acuerdo con el protocolo actual, no fueron descartados en este estudio.

Al analizar los perímetros cefálicos de acuerdo con la desviación estándar, se nota un porcentaje del $60 \%$ de los casos con microcefalia grave. Se entiende que cuanto menor es la desviación estándar, más grave es la microcefalia y, en consecuencia, mayor es la dependencia de este niño ${ }^{(15)}$.

Un estudio realizado en Colombia, país endémico, mostró que durante el desarrollo embrionario hay un incremento en el líquido cefalorraquídeo en el espacio subaracnoideo y en el volumen ventricular, además de la reducción del parénquima cerebral supratentorial, lo que puede acarrear una disminución del tejido cerebral y microcefalia asociada con el ZIKV (28). El virus tiene tropismo por tejido nervioso con efectos teratogénicos, sobre todo en el cerebro del feto, donde los recién nacidos con microcefalia asociada con el Zika tienen deficiencias en el desarrollo neurológico (29). Así, es necesario ofrecer soporte y apoyo a la salud, la educación y al aspecto psicológico de las familias que tuvieron sus hijos afectados por el ZIKV. 
Además, es importante utilizar estándares apropiados de medición y seguimiento para niños, así como promover el monitoreo continuo de casos de microcefalia potencialmente asociados con el ZIKV. Los casos sospechosos deben investigarse y confirmarse a partir de pruebas radiológicas o laboratoriales ${ }^{(30)}$.

En este estudio, 164 niños presentaron alteraciones radiológicas en la prueba de TCC, donde estas alteraciones se segmentaron según la ocurrencia, siendo más frecuentes las calcificaciones, seguidas de malformaciones del desarrollo cortical, alteraciones de la sustancia blanca, lisencefalia y ventriculomegalia. Se debe subrayar que tales datos deben ser evaluados más detalladamente por los especialistas y que la ejecución de la prueba depende de numerosos factores, como la sedación del niño, el ejecutor y el intérprete de la prueba.

En estudios que agruparon niños con o sin alteraciones radiológicas, se encontró el $41 \%$ de las anomalías, donde se subrayaron calcificaciones, ventriculomegalia y lisencefalia ${ }^{(24)}$. Las pruebas de laboratorio para ZIKV y TCC realizadas en 79 casos demostraron que $21(27 \%)$ presentaban anomalías cerebrales significativas en la tomografía (25).

En lo que atañe a las debilidades del estudio, se señala que se utilizaron datos secundarios para evaluar el perfil epidemiológico de los portadores de microcefalia. Es necesario realizar estudios adicionales que puedan demostrar aspectos clínicos y epidemiológicos a largo plazo, con miras a contribuir con mejoras en la calidad de vida de estos portadores.

\section{CONCLUSIONES}

Se propuso este estudio para describir el perfil clínico y epidemiológico de los niños con microcefalia diagnosticados en un brote de 2015 y se espera que contribuya a salvaguardar futuras investigaciones sobre esta enfermedad. Se subraya que la mayoría de los niños que presentan microcefalia grave consecuentemente requerirán una atención multiprofesional especializada a lo largo de sus vidas. Dado que este es un problema de salud pública evitable que debe tener una alta vigilancia permanente, los profesionales, a su vez, necesitarán de capacitación y entrenamiento específicos.

Además, la necesidad de un empeño total con el bebé con funciones cognitivas y motoras comprometidas debe provocar un impacto socioeconómico y tendrá un efecto directo en la calidad de vida de las familias. Así, además de una atención especializada, es necesario brindar apoyo social a estas familias y garantizar el cumplimiento de los derechos relacionados con la salud, la educación y la rehabilitación.

Otro aspecto indispensable es la necesidad de prevención para evitar la aparición de nuevos casos, con acciones de vigilancia epidemiológica y entomológica, medidas educativas coherentes y acciones de control más eficaces en la lucha contra el vector.

\section{REFERENCIAS}

1. Weaver SC, Costa F, Garcia-Blanco MA, Ko Al, Ribeiro GS, Saade G, et al. Zika virus: history, emergence, biology, and prospects for control. Antiviral Res. [Internet] 2016 [cited 2016 Nov 20]; 130:69-80. Available from: https://doi.org/10.1016/j.antiviral.2016.03.010. 
2. Oliveira Melo AS, Malinger G, Ximenes R, Szejnfeld PO, Alves Sampaio S, Bispo de Filippis AM. Zika virus intrauterine infection causes fetal brain abnormality and microcephaly: tip of the iceberg? Ultrasound Obstet Gynecol. [Internet] 2016 [cited 2016 Nov 20]; 47:6-7. Available from: http://onlinelibrary.wiley.com/doi/10.1002/uog.15831/epdf.

3. Mlakar J, Korva M, Tul N, Popović M, Poljšak-Prijatelj M, Mraz J, et al. Zika virus associated with microcephaly. N Engl J Med [Internet] 2016 [cited 2016 Nov 20]; 374:951-8 Available

from:

http://www.nejm.org/doi/full/10.1056/NEJMoa1600651\#t=article.

4. Campos GS, Bandeira AC, Sardi SI. Zika virus outbreak, Bahia, Brazil. Emerg Infect Dis. [Internet] 2015 [cited 2016 Nov 20]; 21:1885-6. Available from: https://www.ncbi.nlm.nih.gov/pmc/articles/PMC4593454/.

5. Dupont-Rouzeyrol M, O'Connor O, Calvez E, Daures M, John M, Grangeon JP, et al. Co-infection with Zika and dengue viruses in 2 patients, New Caledonia, 2014. Emerg Infect Dis. [Internet] 2015 [cited 2016 Nov 20]; 21:381-382. Available from: https://www.ncbi.nlm.nih.gov/pmc/articles/PMC4593454/

6. Baronti C, Piorkowski G, Charrel RN, Boubis L, Leparc-Goffart I, de Lamballierie X. Complete sequence of Zika virus from a French Polynesia outbreak in 2013. Genome Announc [Internet] 2014 [cited 2016 Nov 20]; 2(3):e00500-14. Available from: https://www.ncbi.nlm.nih.gov/pmc/articles/PMC4047448/pdf/e00500-14.pdf

7. Ioos S, Mallet HP, Leparc Goffart I, Gauthier V, Cardoso T, Herida M. Current Zika virus epidemiology and recent epidemics. Med Mal Infect [Internet] 2014 [cited 2016 Nov 20]; 44:302-7. Available from: https://www.ncbi.nlm.nih.gov/pubmed/25001879

8. Oliveira CS, Vasconcelos PFC. Microcephaly and Zika virus. J Pediatr (Rio J) [Internet] 2016 [cited 2016 Nov 20]; 92(2):103-5. Available from: http://www.scielo.br/pdf/jped/v92n2/pt 0021-7557-jped-92-02-0103.pdf

9. Esposito DLA, Moraes JB, Fonseca BAL. Current priorities in the Zica response. Immonology [Internet] 2017 Nov [cited in 17 december 2018];135 (4): 435-442 Available from: https://onlinelibrary.wiley.com/doi/full/10.1111/imm.12878.

10. Javed F, Manzoor KN, Ali M, Haq IU, Khan AA, Zaib A, Manzoor S. Zika virus: what we need to know? J Basic Microbiol. 2018 Nov; 58(1): 3-16.

11. Göertz GP, Abbo SR, Fros JJ, Pijlman GP. Functional RNA during Zika vírus infection. Virus research 2018 Aug; 254: 41-53.

12. Krauer F, Riesen M, Reveiz L, Oladapo OD, Martínez-Veja R, Porgo TV et al. Zika virus Infection as a cause of Congenital Brain Abnormalities and Guillain-Barré Syndrome: Sistematic Review. Plos Med [internet] 2017 Jan[cited in 17 december 2018]; 1-27 Available from: https://www.ncbi.nlm.nih.gov/pmc/articles/PMC5207634/.

13. Organização mundial da saúde. Microcephaly. [Internet] 20162007 [cited 2016 Jun 14]; Available from: http://who.int/mediacentre/factsheets/microcephaly/en/

14. Pryor HB, Thelander $\mathrm{H}$. Abnormally small head size and intellect in children. J Pediatr [Internet] 1968 [cited 2016 Nov 20]; 73:593-598. Available from: http://www.jpeds.com/article/S0022-3476(68)80275-6/pdf

15. Coronado R, Ruíz AM, Arjonilla JG, Roig-Quilis M. Concordancia entre una función de crecimiento del perímetro cefálico y la discapacidad intelectual em relación con la etiología de la microcefalia. An Pediatr (Barc). [Internet] 2015 [cited 2016 Nov 20]; 83(2):109-116. Available from: http://www.analesdepediatria.org/es-pdfS1695403314005311

16. Brasil. Centro de Operações de Emergências em Saúde Pública Sobre Microcefalias - COES - MICROCEFALIAS. Monitoramento dos Casos de Microcefalia no Brasil. Informe epidemiológico n 37 - Semana Epidemiológica (SE) 30/2016 (24/07/2016 a 30/07/2016). Brasília; 2016. Disponível em: 
http://combateaedes.saude.gov.br/images/sala-de-

situacao/informe microcefalia epidemiologico37.pdf

17. Pernambuco. Secretaria Estadual de Saúde de Pernambuco. Secretaria Executiva de Vigilância em Saúde. Protocolo Clínico e Epidemiológico para investigação de casos de microcefalia no estado de Pernambuco. Versão № 02; 2015. Disponível em: http://portal.saude.pe.gov.br/sites/portal.saude.pe.gov.br/files/protocolo microcefalia versao02.pdf

18. Nunes ML, Carlini CR, Marinowic D, Neto FK, Fiori HH, Scotta MC, et al. Microcephaly and Zika virus: a clinical and epidemiological analysis of the current outbreak in Brazil. J Pediatr (Rio J) [Internet] 2016 [cited 2016 Nov 20]; 92(3):230240. Available from: https://doi.org/10.1016/j.jped.2016.02.009

19. Noronha Ld, Zanluca C, Azevedo ML, Luz KG, Santos CN. Zika virus damages the human placental barrier and presents marked fetal neurotropism. Mem Inst Oswaldo Cruz [Internet] 2016 [cited 2016 Nov 20]; 111(5):287-293. Available from: https://www.ncbi.nlm.nih.gov/pmc/articles/PMC4878297/pdf/0074-0276-mioc-111-50287.pdf

20. Araújo TVB, Ximenes RAA, Filho DBM, Rodrigues LC, Souza WV, Montarroyos UR, Melo APL, et al. Association between microcephaly, Zika virus infection, and other risk factors in Brazil: final report of a case-control study. Lancet Infect Dis [Internet] 2018 [cited 2018 Jul 22]; 18:328-36. Available from: https://www.thelancet.com/pdfs/journals/laninf/PIIS1473-3099(17)30727-2.pdf

21. Duffy MR, Chen TH, Hancock WT, Powers AM, Kool JL, Lanciotti RS, et al. Zika virus outbreak on Yap Island, Federated States of Micronesia. N Engl J Med [Internet] 2009 [cited 2016 Nov 20]; 360:2536-43. Available from: http://www.nejm.org/doi/pdf/10.1056/NEJMoa0805715

22. Brasil P, Pereira JP Jr, Raja Gabaglia C, Nogueira RMR, Damasceno L, Wakimoto $M$, et al. Zika virus infection in pregnant women in Rio de Janeiro - preliminary report. N Engl J Med. [Internet] 2016 [cited 2016 Nov 20]; 24(375): 2321-34. Available from: http://www.nejm.org/doi/pdf/10.1056/NEJMoa1602412

23. Serpa LLN, Costa KVRM, Voltolini JC, Kakitani I. Variação sazonal de Aedes aegypti e Aedes albopictus no município de Potim, São Paulo. Rev Saúde Pública. [Internet] 2006 [citado 20 Nov 2016]; 40:1101-1105. Disponível em: http://www.scielo.br/pdf/rsp/v40n6/20.pdf

24.Vissoci JRN, Rocha TAH, Silva NC, Queiroz RCS, Thomaz EBAF, Amaral PVM et al. Zica virus infection and mycrocephaly: Evidence regarding geoespatial associations. PloS Neg Trop Des [Internet] 2018 Apr [cited in: 17 december 2018] 12(4): e0006392. Available from: https://journals.plos.org/plosntds/article?id=10.1371/journal.pntd. 0006392

25. Brasil. Ministério da Saúde. Nota Informativa N01/2015 - COES Microcefalias. Brasília (DF), 17 de novembro de 2015. Disponível em: http://www.cosemspa.com.br/wordpress/wp-content/uploads/2015/11/microcefalianota-informativa-17nov2015-c-1.pdf

26. Brasil. Ministério da Saúde. Protocolo de vigilância e resposta à ocorrência de microcefalia relacionada à infecção pelo vírus Zika. Brasília, 2015. Disponível em: http://portalarquivos.saude.gov.br/images/pdf/2015/dezembro/09/Microcefalia---

Protocolo-de-vigil--ncia-e-resposta---vers--o-1----09dez2015-8h.pdf

27. Brasil. Ministério da Saúde. Protocolo de vigilância e resposta à ocorrência de microcefalia e/ou alterações do sistema nervoso central (SNC) Brasília, 2016. Disponível em: http://combateaedes.saude.gov.br/images/sala-desituacao/Microcefalia-Protocolo-de-vigilancia-e-resposta-10mar2016-18h.pdf

28. Cortes MS, Rivera AM, Yepez M, Guimaraes CV, Yunes ID, Zarutskie A et al. Clinical assessment and brain findings in a cohort of mothers, fetuses and infants 
infected with Zika virus. Am J Obstet Gynecol [Internet] 2018 Apr [cited in 17 decmber 2018]; 218(4):440.e1-440.e36. Available from: https://www.ajog.org/article/S00029378(18)30013-9/fulltext

29. Pereira AM, Monteiro DLM, Werner E, Daltro P, Fazecas T, Guedes B et al. Zica virus and pragnancy in Brazil: what hapenned? J Turk Ger Gynecol Assoc [Internet] 2018 [cited in 17 december 2018]; 19(1): 39-47. Available from: https://www.ncbi.nlm.nih.gov/pmc/articles/PMC5838777/

30. Victora CG, Schuler-Faccini L, Matijasevich A, Ribeiro E, Pessoa A, Barros FC. Microcephaly in Brazil: how to interpret reported numbers? Lancet 2016 Feb;387(10019):621-4. 